\title{
PERENCANAAN PAKET WISATA BUDAYA DI DESA KESIMAN KECAMATAN DENPASAR TIMUR
}

\author{
I Made Pradnya Sutara \\ I Ketut Suwena \\ I Wayan Suardana \\ Email : emondiablosatanic@gmail.com \\ PS. S1 Industri Perjalanan Wisata \\ Fakultas Pariwisata UNUD
}

\begin{abstract}
Bali have one city, it is Denpasar City, within tourism potencies that can be build to be package tours. Kesiman Traditional Village is one of many villages in Denpasar City that has many tourism potency, the potency is cultural tourism potencies that can be found, such as : art attraction, historical place, traditional fashion and food, villager activities based on culture, hospitality of the villagers. Those cultural Potencies which found in Kesiman Traditional Village can be pack to be cultural package tours. Regard to planning cultural package tour, the formulation of issues are: (1) What is the potencies that can be found in Kesiman Traditional Village, East Denpasar? (2) How the planning cultural package in Kesiman Traditional Village?

The technique to collecting data did through observation, interviews, documentation, and books literature. The result of the research is known that Kesiman Traditional Village has cultural tourism potencies and those potencies can be package into cultural package tour, those are : Barong and Keris Dance, Wadah Maker, Pengrebongan Temple, Kesiman Castle, Odah Turut Balinese House, Balinese Dance and Music Lesson in Bale Banjar Ceramcam Kesiman, Made Sudyatmika Paint Lesson, Ananda Balinese Boutique, Kertalangu Tourist Village with jogging track surrounded by rice field, fishing pond, and World Peace Gong, and Kroya Kites House. Those potencies then package into planning cultural package tour in the form of tables, essay, and graphic. Those are package into cultural package tour, those are: (1) History and Spirit of Kesiman Cultural Tour, (2) Beautiful Art of Kesiman Cultural Tour, (3) Art and Local Activities of Kesiman Cultural Tour.
\end{abstract}

\section{Keywords : Potencies, Cultural Tourism, Package Tour}

\section{LATAR BELAKANG}

Bali merupakan pulau yang memiliki banyak potensi wisata. Sebagai suatu destinasi wisata, Bali dapat memberikan kepastian akan kepuasan dan kenyamanan bagi wisatawan. Perkembangan pariwisata di Bali didukung oleh berbagai fasilitas penunjang seperti : hotel, travel agent, restoran, atraksi wisata menarik dengan beraneka ragam daya tarik wisata. Bali memiliki ciri khas dalam daya tarik wisata. Keindahan alam, adat istiadat, kebudayaan, dan kehidupan keseharian masyarakatnya yang bernuansa Hindu, dapat menarik minat wisatawan nusantara ataupun mancanegara berkunjung ke Bali.

Denpasar merupakan pusat kota Provinsi Bali. Di kota ini banyak penduduk luar kota Denpasar atau luar Bali tinggal dan bekerja di Bali. Di samping sebagai daerah pariwisata, Denpasar juga dapat disebut sebagai kota pendidikan, karena ada banyak sekolah dari tingkat dasar sampai perguruan tinggi.

Keseharian masyarakat kota Denpasar yang tidak pernah lepas dengan adat - istiadat, melakukan upacara adat sesuai dengan kebiasaan nenek moyang terdahulu. Adat istiadat yang telah dilakukan oleh nenek 
moyangnya sampai saat ini masih tetap dilakukan meskipun sudah ada masuk budayabudaya luar.

Kota Denpasar memiliki banyak potensi budaya yang dapat menarik minat wisatawan untuk berkunjung, baik wisatawan domestik maupun mancanegara. Perkembangan kepariwisataan kota Denpasar cukup baik. Denpasar memiliki potensi wisata yang dapat menarik kunjungan wisatawan yaitu potensi wisata budaya dengan aktivitas seni dan budaya yang marak di Kota Denpasar. Selain itu, Denpasar memiliki tempat-tempat untuk memamerkan kebudayaan Bali, seperti Taman Budaya Art Centre, dan Museum Bali.

Salah satu desa di Kota Denpasar yang terkenal akan budayanya yaitu Desa Kesiman. Desa Kesiman memiliki berbagai potensi budaya. Adapula potensi wisata yang sudah terkenal yaitu, Desa Wisata Kertalangu dan Barong and Keris Dance. Namun sempat mengalami penurunan kunjungan pada tahun 2012 yang disebabkan oleh kurangnya paket wisata yang dikembangkan sehingga masih terkesan monoton.

Masih banyak potensi wisata budaya yang belum terjamah di Desa Kesiman seperti industri rumah tangga, kuliner, seni budaya dan kerajinan tangan yang dihasilkan oleh masyarakat lokal, sehingga potensi yang ada tersebut perlu untuk digali. Dengan adanya potensi yang lebih bervariasi, maka akan dapat menarik wisatawan untuk berkunjung, serta potensi tersebut dapat dikembangkan menjadi suatu daya tarik wisata.

Upaya menggali potensi-potensi wisata agar dapat dijadikan daya tarik wisata, baik dari hiburan, alam maupun budaya semua ini ada di Desa Kesiman. Desa Kesiman merupakan desa yang kaya akan potensi wisata budaya. Desa Kesiman memiliki budaya "ngerebong". Dalam upacara tersebut diiringi oleh tabuh ancag ancagan yang khas, wisata kuliner, sanggar tari, puri, sekaa gong, pembuatan panggul gamelan, pembuatan babi guling, pembuatan jajanan Bali, pembuatan sarana upacara Hindu, pembuatan layangan tradisional, dan yang tidak kalah menariknya adalah pembuatan wadah untuk upacara ngaben di Bali.

Desa Kesiman memiliki banyak potensi wisata dan dapat dijadikan daerah tujuan wisata.
Potensi tersebut bisa dikemas menjadi sebuah paket wisata. Puri Kesiman yang merupakan tonggak sejarah Desa Kesiman, masyarakat Desa Kesiman yang bernuansa Hindu Bali, aneka kerajinan, dan masih banyak potensi lainnya yang dapat dilihat dari dusun ke dusun di Desa Kesiman. Semua itu dapat dikemas dalam bentuk paket wisata sehingga dapat disajikan kepada wisatawan untuk menarik minat wisatawan untuk datang berkunjung ke Desa Kesiman.

\section{METODE PENELITIAN}

Lokasi terletak di Desa Kesiman, Kecamatan Denpasar Timur Kota Denpasar. Tinjauan pustaka yang digunakan adalah tinjauan tentang pariwisata dengan teori Yoeti (1991), tinjauan tentang potensi wisata dengan teori Yoeti (2002), tinjauan tentang perencanaan dengan teori Soekidjo Notoatmojo (2003), tinjauan tentang paket wisata dengan teori Suyitno (2001), tinjauan tentang desa wisata budaya dengan teori Nuryanti (1992), tinjauan tentang pariwisata budaya dengan teori Boniface (1995).

Teknik pengumpulan data yang digunakan yaitu dengan cara observasi, wawancara, studi kepustakaan dan dokumentasi. Teknik penentuan informan kemudian dibagi menjadi dua yaitu informan pangkal dan informan kunci. Informan kunci disini adalah Bendesa Desa Adat Kesiman beserta tokoh - tokoh masyarakat. Sedangkan yang merupakan informan pangkal adalah Dinas Pariwisata dan Budaya Daerah Kota Madya Denpasar. Teknik analisis data yang digunakan adalah analisis deskriptif kualitatif dan deskriptif kuantitatif.

\section{HASIL}

Dapat diketahui di Desa Kesiman terdapat sepuluh potensi wisata yang dapat disusun untuk dijadikan paket wisata budaya. Potensi - potensi wisata budaya tersebut antara lain adalah, Barong and Keris Dance, Tempat Pembuatan Wadah, Pura Pengrebongan Kesiman, Puri Kesiman, Rumah Bali Odah Turut, Bale Banjar Ceramcam, Sanggar Lukis Made Sudyatmika, Ananda Balinese Boutique, Desa Wisata Kertalangu, dan Rumah Layangan Kroya yang 
merupakan potensi yang didalamnya terdapat aktivitas yang dapat menarik wisatawan dan memberikan suatu pengalaman yang berkesan.

Barong and Keris Dance mempertunjukan tarian barong. Barong merupakan salah satu karakter yang terkenal dari Bali yang dalam kepercayaan merupakan jelmaan dari Dewa. Dalam Pertunjukan Barong juga akan dilengkapi oleh pelawak dan gamelan yang penuh semangat

Tempat Pembuatan Wadah merupakan tempat usaha pembuatan wadah yang merupakan sarana upacara ngaben bagi umat Hindu di Bali. Selain wadah, disini juga membuat beraneka jenis petulangan seperti lembu, dan lainnya.

Pura Pengrebongan Kesiman adalah pura di Desa Kesiman yang terkenal dengan upacara ngerebong. Upacara tersebut diselenggarakan di Desa Kesiman setiap enam bulan sekali. Arsitektur pura juga sangat menarik.

Puri Kesiman merupakan tempat bersejarah karena merupakan sebuah kerajaan di Desa Kesiman sebelum sistem kepemerintahan berubah menjadi republik. Puri Kesiman ikut berjuang dalam perang Puputan Badung pada era penjajahan Belanda.

Rumah Bali Odah Turut merupakan rumah yang didalamnya terdapat usaha pembuatan jajanan khas Bali dan berbagai sarana upacara. Disini akan dijelaskan proses pembuatan jajan dan sarana upacara tersebut.

Bale Banjar Ceramcam merupakan suatu tempat atau banjar yang terdapat organisasi sanggar seni didalamnya. Disini akan diajarkan untuk menari tarian Bali dan belajar memainkan gamelan Bali.

Sanggar Lukis Made Sudyatmika merupakan suatu sanggar lukis yang mengajarkan teknik untuk melukis berbagai budaya khas bali. Disini juga terdapat usaha pembuatan aneka sarana upacara seperti Bandrang, Tedung, dan berbagai jenis sarana upacara lain.

Ananda Balinese Boutique merupakan tempat penjualan busana adat Bali. Disini wisatawan dapat belajar mengenakan busana adat dan berbelanja apabila tertarik.

Desa Wisata Kertalangu merupakan daya tarik yang didalamnya terdapat berbagai jenis hiburan. Disini juga terdapat jogging track yang dikelilingi areal pesawahan yang hijau serta kolam pancing.
Rumah Layangan Kroya merupakan tempat pembuatan berbagai jenis layangan tradisional Bali. Disini dapat melihat bagaimana proses pembuatan layangan tradisional tersebut, selain itu dapat membeli apabila tertarik.

Seluruh potensi tersebut kemudian disusun dalam tiga buah paket wisata budaya yaitu, History and Spirit of Kesiman Cultural Tour, Beautiful Art of Kesiman Cultural Tour, dan Art and Local Activities of Kesiman Cultural Tour. Ketiga paket tersebut juga dibuat dalam bentuk tabel, grafik dan harga paket.

History and Spirit of Kesiman Cultural Tour mengambil rute perjalanan yang diawali dengan Barong and Keris Dance, Pura Pengrebongan, Tempat Pembuatan Wadah, Puri Kesiman, Rumah Bali Odah Turut, Ananda Balinese Boutique, Desa Wisata Kertalangu dan kembali ke hotel.

Beautiful Art of Kesiman Cultural Tour mengambil rute perjalanan yang diawali dengan Barong and Keris Dance, Pura Pengrebongan, Rumah Layangan Kroya, Bale Banjar Ceramcam (Sanggar Tari Dedari Swadharmita), Ananda Balinese Boutique, Desa Wisata Kertalangu dan kembali ke hotel.

Art and Local Activities of Kesiman Cultural Tour mengambil rute perjalanan yang diawali dengan Barong and Keris Dance, Bale Banjar Ceramcam (Sanggar Tari Dedari Swadharmita), Sanggar Lukis Made Sudyatmika, Desa Wisata Kertalangu dan kembali ke hotel.

\section{PEMBAHASAN}

Potensi - potensi wisata budaya yang ada di desa kesiman disusun dalam tiga buah paket wisata budaya, yaitu History and Spirit of Kesiman Cultural Tour, Beautiful Art of Kesiman Cultural Tour, dan Art and Local Activities of Kesiman Cultural Tour. Masing masing paket wisata tersebut kemudian dijelaskan dalam bentuk tabel, grafik, dan harga paket.

Tabel mejelaskan tentang rangkaian acara dan durasi yang dilakukan wisatawan dalam perjalanan, grafik akan menjelaskan bentuk jalur perjalanan yang disertai jarak dan waktu tempuh, dan harga paket menjelaskan tentang 


\begin{tabular}{|c|c|c|c|c|}
\hline T'empat & $\begin{array}{c}\text { Wak } \\
\text { tu }\end{array}$ & $\begin{array}{l}\text { Dur } \\
\text { asi }\end{array}$ & Acara & $\begin{array}{c}\text { Keterang } \\
\text { an }\end{array}$ \\
\hline $\begin{array}{l}\text { Hotel/Kut } \\
\text { Jurnal IPTA } \\
\text { Vol. } 4 \text { No. }\end{array}$ & $\begin{array}{c}08.0 \\
0 \\
1,2016\end{array}$ & $\begin{array}{c}30 \\
\text { men } \\
\text { it }\end{array}$ & $\begin{array}{c}\text { Persiapa } \\
\mathrm{n} \\
\text { memulai } \\
\text { tour } \\
\text { (berangk } \\
\text { at) }\end{array}$ & \\
\hline $\begin{array}{c}\text { Barong } \\
\text { and Keris } \\
\text { Dance }\end{array}$ & $\begin{array}{c}09.2 \\
0\end{array}$ & $\begin{array}{c}70 \\
\text { men } \\
\text { it }\end{array}$ & $\begin{array}{c}\text { Wisataw } \\
\text { an } \\
\text { menonto } \\
\mathrm{n} \\
\text { pertunju } \\
\text { kan } \\
\text { Barong } \\
\end{array}$ & $\begin{array}{c}\text { Pramuwi } \\
\text { sata } \\
\text { menjelas } \\
\text { kan } \\
\text { tentang } \\
\text { Barong }\end{array}$ \\
\hline $\begin{array}{c}\text { Pura } \\
\text { Pengrebo } \\
\text { ngan } \\
\text { Kesiman }\end{array}$ & $\begin{array}{c}10.5 \\
0\end{array}$ & $\begin{array}{c}35 \\
\text { men } \\
\text { it }\end{array}$ & $\begin{array}{c}\text { Wisataw } \\
\text { an } \\
\text { mengelil } \\
\text { ingi } \\
\text { kawasan } \\
\text { pura dan } \\
\text { berfoto }\end{array}$ & $\begin{array}{c}\text { Pramuwi } \\
\text { sata } \\
\text { memberi } \\
\text { kan } \\
\text { briefing } \\
\text { dan } \\
\text { menjelas } \\
\text { kan } \\
\text { tentang } \\
\text { pura }\end{array}$ \\
\hline $\begin{array}{c}\text { Tempat } \\
\text { Pembuata } \\
\text { n Wadah }\end{array}$ & $\begin{array}{c}11.4 \\
5\end{array}$ & $\begin{array}{c}20 \\
\text { men } \\
\text { it }\end{array}$ & $\begin{array}{c}\text { Wisataw } \\
\text { an } \\
\text { melihat } \\
\text { dan } \\
\text { membant } \\
\text { u proses } \\
\text { pembuat } \\
\text { an }\end{array}$ & $\begin{array}{c}\text { Pramuwi } \\
\text { sata } \\
\text { menjelas } \\
\text { kan } \\
\text { fungsi } \\
\text { dan jenis } \\
\text { dari } \\
\text { wadah } \\
\end{array}$ \\
\hline $\begin{array}{c}\text { Puri } \\
\text { Kesiman }\end{array}$ & $\begin{array}{c}12.2 \\
0\end{array}$ & $\begin{array}{c}30 \\
\text { men } \\
\text { it }\end{array}$ & $\begin{array}{c}\text { Wisataw } \\
\text { an } \\
\text { mengelil } \\
\text { ingi } \\
\text { kawasan } \\
\text { puri dan } \\
\text { berfoto }\end{array}$ & $\begin{array}{c}\text { Pramuwi } \\
\text { sata } \\
\text { memberi } \\
\text { kan } \\
\text { briefing } \\
\text { dan } \\
\text { menjelas } \\
\text { kan } \\
\text { tentang } \\
\text { puri }\end{array}$ \\
\hline Lunch & $\begin{array}{c}13.3 \\
0\end{array}$ & $\begin{array}{c}60 \\
\text { men } \\
\text { it } \\
\end{array}$ & & \\
\hline $\begin{array}{c}\text { Rumah } \\
\text { Bali Odah } \\
\text { Turut }\end{array}$ & $\begin{array}{c}14.1 \\
0\end{array}$ & $\begin{array}{c}60 \\
\text { men } \\
\text { it }\end{array}$ & $\begin{array}{c}\text { Wisataw } \\
\text { an } \\
\text { mempela } \\
\text { jari } \\
\text { proses } \\
\text { pembuat } \\
\text { an jajan } \\
\text { Bali dan } \\
\text { Canang } \\
\end{array}$ & $\begin{array}{c}\text { Pramuwi } \\
\text { sata } \\
\text { menjelas } \\
\text { kan } \\
\text { tentang } \\
\text { rumah } \\
\text { Bali }\end{array}$ \\
\hline $\begin{array}{c}\text { Ananda } \\
\text { Balinese } \\
\text { harga.pake } \\
\text { Botitique }\end{array}$ & $\begin{array}{c}15.3 \\
5 \\
\text { yang } d\end{array}$ & $\begin{array}{c}45 \\
\text { men } \\
\text { sesuail } \\
\text { it }\end{array}$ & $\begin{array}{l}\text { Wisataw } \\
\text { an } \\
\text { an dengan } \\
\text { belajar } \\
\text { mengena }\end{array}$ & an \\
\hline
\end{tabular}

ISSN : 2338-8633

jenis kendaraan.

Berikut dapat dilihat tabel History and Spirit of Kesiman Cultural Tour.

Bentuk Tabel

History and Spirit of Kesiman Cultural Tour

Pada tabel tersebut dijelaskan perjalanan yang dilakukan wisatawan mulai dari kegiatan awal yang dimulai di hotel hingga kembali ke hotel disertai durasi dan waktu. Paket wisata ini mengambil beberapa tempat yang memiliki sejarah menarik dan wisatawan dapat melihat semangat masyarakat Desa Kesiman dalam melakukan kegiatan kebudayaan.

Bentuk tabel dari Beautiful Art of Kesiman Cultural Tour dapat dilihat dalam gambar berikut ini.

\section{Bentuk Tabel \\ Beautiful Art of Kesiman Cultural Tour}

\begin{tabular}{|c|c|c|c|c|}
\hline Tempat & $\begin{array}{c}\text { Wakt } \\
\mathrm{u}\end{array}$ & $\begin{array}{c}\text { Dura } \\
\text { si }\end{array}$ & Acara & $\begin{array}{c}\text { Keterang } \\
\text { an }\end{array}$ \\
\hline $\begin{array}{c}\text { Hotel/Kut } \\
\text { a }\end{array}$ & 08.00 & $\begin{array}{c}30 \\
\text { menit }\end{array}$ & $\begin{array}{l}\text { Persiapan } \\
\text { memulai } \\
\text { tour } \\
\text { (berangk } \\
\text { at) }\end{array}$ & \\
\hline $\begin{array}{c}\text { Barong } \\
\text { and Keris } \\
\text { Dance }\end{array}$ & 09.20 & $\begin{array}{c}70 \\
\text { menit }\end{array}$ & $\begin{array}{c}\text { Wisataw } \\
\text { an } \\
\text { menonto } \\
\mathrm{n} \\
\text { pertunjuk } \\
\text { an } \\
\text { Barong } \\
\end{array}$ & $\begin{array}{c}\text { Pramuwi } \\
\text { satamenj } \\
\text { elaskan } \\
\text { tentang } \\
\text { Barong }\end{array}$ \\
\hline $\begin{array}{c}\text { Pura } \\
\text { Pengrebon } \\
\text { gan } \\
\text { Kesiman }\end{array}$ & 10.50 & $\begin{array}{c}35 \\
\text { menit }\end{array}$ & $\begin{array}{c}\text { Wisataw } \\
\text { an } \\
\text { mengelili } \\
\text { ngi } \\
\text { kawasan } \\
\text { pura dan } \\
\text { berfoto }\end{array}$ & $\begin{array}{l}\text { Pramuwi } \\
\text { sata } \\
\text { memberi } \\
\text { kan } \\
\text { briefing } \\
\text { dan } \\
\text { menjelas } \\
\text { kan }\end{array}$ \\
\hline
\end{tabular}




\begin{tabular}{|c|c|c|c|c|}
\hline & & & & $\begin{array}{l}\text { tentang } \\
\text { pura }\end{array}$ \\
\hline $\begin{array}{c}\text { Rumah } \\
\text { Layangan }\end{array}$ & 11.45 & $\begin{array}{c}60 \\
\text { menit }\end{array}$ & $\begin{array}{c}\text { Wisataw } \\
\text { an } \\
\text { berbelanj } \\
\text { a, } \\
\text { melihat } \\
\text { dan } \\
\text { belajar } \\
\text { membuat } \\
\text { layangan }\end{array}$ & $\begin{array}{l}\text { Pramuwi } \\
\text { sata } \\
\text { menjelas } \\
\text { kan } \\
\text { tentang } \\
\text { layangan } \\
\text { dan } \\
\text { mitosnya }\end{array}$ \\
\hline $\begin{array}{c}\text { Banjar } \\
\text { Ceramcam } \\
\text { (Sanggar } \\
\text { Tari dan } \\
\text { Tabuh) }\end{array}$ & 12.55 & $\begin{array}{c}60 \\
\text { menit }\end{array}$ & $\begin{array}{c}\text { Wisataw } \\
\text { an belajar } \\
\text { memaink } \\
\text { an } \\
\text { gamelan } \\
\text { dan } \\
\text { menari }\end{array}$ & \\
\hline Lunch & 14.10 & $\begin{array}{c}60 \\
\text { menit }\end{array}$ & & \\
\hline $\begin{array}{l}\text { Ananda } \\
\text { Balinese } \\
\text { Boutique }\end{array}$ & 15.10 & $\begin{array}{c}35 \\
\text { menit }\end{array}$ & $\begin{array}{c}\text { Wisataw } \\
\text { an belajar } \\
\text { mengena } \\
\text { kan } \\
\text { busana } \\
\text { adat dan } \\
\text { berbelanj } \\
\text { a } \\
\end{array}$ & \\
\hline $\begin{array}{c}\text { Kertalang } \\
\mathrm{u}\end{array}$ & 16.10 & $\begin{array}{c}55 \\
\text { menit }\end{array}$ & $\begin{array}{l}\text { Wisataw } \\
\text { an } \\
\text { mengelili } \\
\text { ngi } \\
\text { jogging } \\
\text { track dan } \\
\text { memanci } \\
\text { ng }\end{array}$ & $\begin{array}{c}\text { Pramuwi } \\
\text { sata } \\
\text { menjelas } \\
\text { kan } \\
\text { tentang } \\
\text { petani } \\
\text { dan } \\
\text { nelayan } \\
\text { di Bali }\end{array}$ \\
\hline Hotel & 17.55 & & $\begin{array}{l}\text { Wisataw } \\
\text { an tiba } \\
\text { dan } \\
\text { kembali } \\
\text { beristirah } \\
\text { at }\end{array}$ & $\begin{array}{l}\text { Pramuwi } \\
\text { sata } \\
\text { mengece } \\
\text { k bawaan }\end{array}$ \\
\hline
\end{tabular}

Pada tabel tersebut dijelaskan perjalanan yang dilakukan wisatawan mulai dari kegiatan awal yang dimulai di hotel hingga kembali ke hotel disertai durasi dan waktu. Paket wisata ini menyajikan produk seni dan budaya beserta proses kegiatannya yang menggambarkan kegiatan kebudayaan tersebut sehingga wisatawan mendapatkan pengalaman yang indah dalam paket wisata ini.

Bentuk tabel dari Art and Local Activites of Kesiman Cultural Tour dapat dilihat dalam gambar berikut ini.

Bentuk Tabel

Art and Local Activities of Kesiman Cultural Tour 
Vol. 4 No. 1, 2016

\begin{tabular}{|c|c|c|c|c|}
\hline Tempat & $\begin{array}{c}\text { Wakt } \\
\mathrm{u}\end{array}$ & $\begin{array}{c}\text { Dura } \\
\text { si }\end{array}$ & Acara & $\begin{array}{c}\text { Keterang } \\
\text { an }\end{array}$ \\
\hline $\begin{array}{c}\text { Hotel/Kut } \\
\text { a }\end{array}$ & 08.00 & $\begin{array}{c}30 \\
\text { menit }\end{array}$ & $\begin{array}{c}\text { Persiapan } \\
\text { memulai } \\
\text { tour } \\
\text { (berangk } \\
\text { at) }\end{array}$ & \\
\hline $\begin{array}{c}\text { Barong } \\
\text { and Keris } \\
\text { Dance }\end{array}$ & 09.20 & $\begin{array}{c}70 \\
\text { menit }\end{array}$ & $\begin{array}{c}\text { Wisataw } \\
\text { an } \\
\text { menonto } \\
\mathrm{n} \\
\text { pertunjuk } \\
\text { an } \\
\text { Barong } \\
\end{array}$ & $\begin{array}{c}\text { Pramuwi } \\
\text { sata } \\
\text { menjelas } \\
\text { kan } \\
\text { tentang } \\
\text { Barong }\end{array}$ \\
\hline $\begin{array}{c}\text { Banjar } \\
\text { Ceramcam } \\
\text { (Sanggar } \\
\text { Tari dan } \\
\text { Tabuh) }\end{array}$ & 10.55 & $\begin{array}{c}120 \\
\text { menit }\end{array}$ & $\begin{array}{c}\text { Wisataw } \\
\text { an belajar } \\
\text { memaink } \\
\text { an } \\
\text { gamelan } \\
\text { dan } \\
\text { menari }\end{array}$ & \\
\hline $\begin{array}{l}\text { Sanggar } \\
\text { Lukis }\end{array}$ & 13.10 & $\begin{array}{c}80 \\
\text { menit }\end{array}$ & $\begin{array}{l}\text { Wisataw } \\
\text { an belajar } \\
\text { melukis }\end{array}$ & \\
\hline Lunch & 15.00 & $\begin{array}{c}60 \\
\text { menit }\end{array}$ & & \\
\hline $\begin{array}{c}\text { Kertalang } \\
\mathrm{u}\end{array}$ & 16.00 & $\begin{array}{c}55 \\
\text { menit }\end{array}$ & $\begin{array}{c}\text { Wisataw } \\
\text { an } \\
\text { mengelili } \\
\text { ngi } \\
\text { jogging } \\
\text { track dan } \\
\text { memanci } \\
\text { ng }\end{array}$ & $\begin{array}{c}\text { Pramuwi } \\
\text { sata } \\
\text { menjelas } \\
\text { kan } \\
\text { tentang } \\
\text { petani } \\
\text { dan } \\
\text { nelayan } \\
\text { di Bali }\end{array}$ \\
\hline Hotel & 17.45 & & $\begin{array}{c}\text { Wisataw } \\
\text { an tiba } \\
\text { dan } \\
\text { kembali } \\
\text { beristirah } \\
\text { at }\end{array}$ & $\begin{array}{l}\text { Pramuwi } \\
\text { sata } \\
\text { mengece } \\
\text { k bawaan }\end{array}$ \\
\hline
\end{tabular}

Bentuk Grafik

History and Spirit of Kesiman Cultural Tour

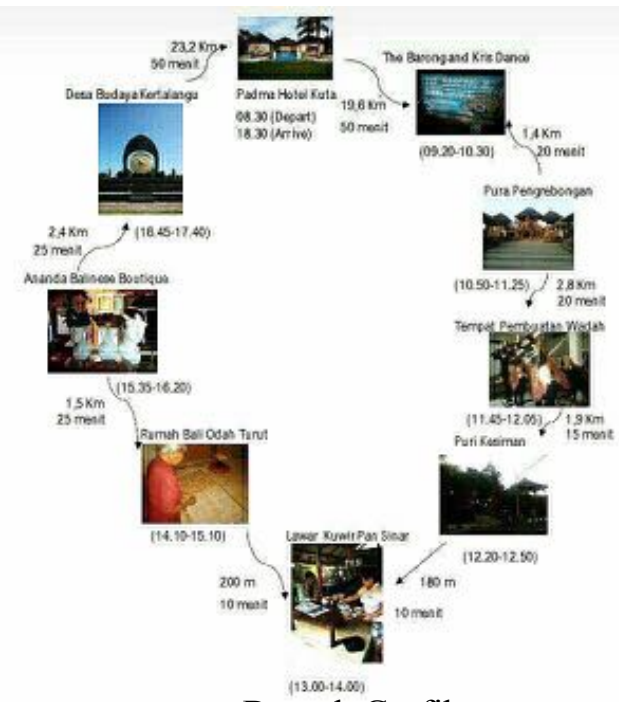

Bentuk Grafik

Beautiful Art of Kesiman Cultural Tour

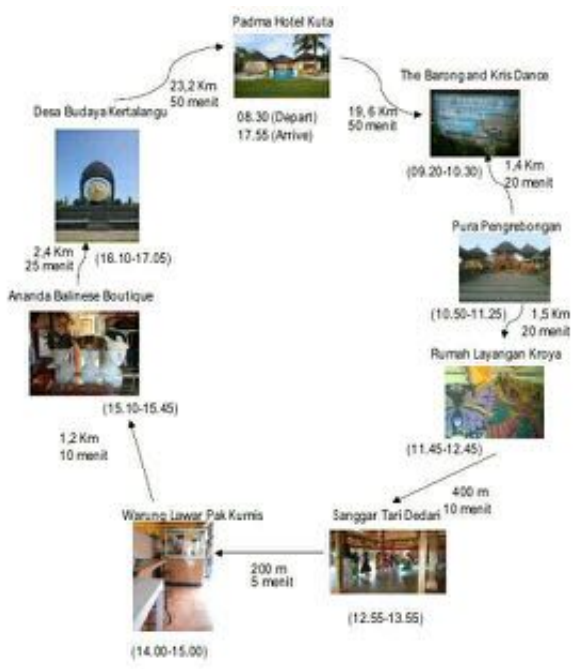

Bentuk Grafik

Art and Local Activities of Kesiman Cultural Tour

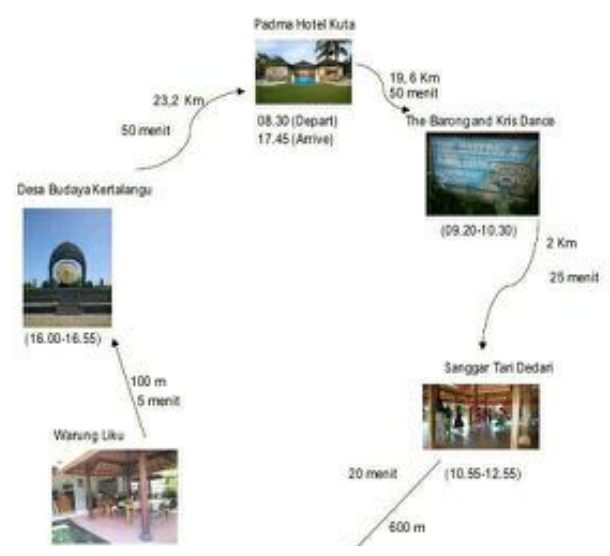


Dalam bentuk grafik tersebut dijelaskan bentuk jalur yang akan ditempuh oleh wisatawan selama perjalanan. Selain itu, grafik juga dilengkapi dengan durasi waktu yang dihabiskan di masing - masing daya tarik yang tertera di paket wisata, dan juga waktu dan jarak tempuh antar daya tarik wisata dalam masing - masing paket.

Berikutnya akan dijelaskan harga paket dari masing - masing paket.

\section{Harga Paket}

History and Spirit of Kesiman Cultural Tour

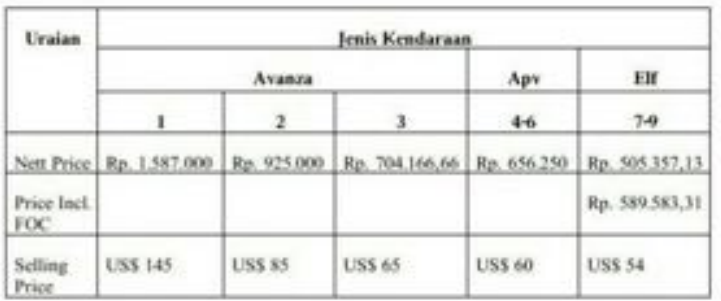

Harga Paket

Beautiful Art of Kesiman Cultural Tour

\begin{tabular}{|c|c|c|c|c|c|}
\hline \multirow[t]{3}{*}{ Uraias } & \multicolumn{5}{|c|}{ Jenis Kendarkan } \\
\hline & \multicolumn{3}{|c|}{ Avanza } & $A p y$ & EII \\
\hline & 1 & 2 & 3 & 46 & 79 \\
\hline Nett Price & $\operatorname{Rp} 1612.500$ & Rp 950000 & $R_{p} .729 .106 .06$ & $\operatorname{Rp} 681250$ & Bes 530357,13 \\
\hline $\begin{array}{l}\text { Prive Ind. } \\
\text { FOC }\end{array}$ & & & & & He, $687.499,97$ \\
\hline $\begin{array}{l}\text { Selling } \\
\text { Prose }\end{array}$ & USs 147 & USS 87 & Us5 67 & USs 63 & USs 57 \\
\hline
\end{tabular}

Harga Paket

Art and Local Activities of Kesiman Cultural Tour

\begin{tabular}{|c|c|c|c|c|c|}
\hline \multirow[t]{3}{*}{ Uraian } & \multicolumn{5}{|c|}{ Jenis Kendarean } \\
\hline & \multicolumn{3}{|c|}{ Avanza } & Apv & DH \\
\hline & 1 & 2 & 3 & $4-6$ & 79 \\
\hline Netl Price & $R_{p} .1 .468 .750$ & Rp $_{p} 900000$ & $R_{p} .710 .416 .66$ & $R=67 x .125$ & $R_{p} .547 .321,42$ \\
\hline $\begin{array}{l}\text { Prive Incl. } \\
\text { FOC }\end{array}$ & & & & & kp. 638541,65 \\
\hline $\begin{array}{l}\text { Selling } \\
\text { Prise }\end{array}$ & USS 134 & USs \&2 & Uss 65 & Uss 62 & USS 59 \\
\hline
\end{tabular}

Dalam harga paket tersebut dijelaskan harga dari masing - masing paket wisata yang telah disesuaikan dengan jenis kendaraan, jumlah wisatawan, dan biaya perjalanan dengan dasar Confidential Agent Tarif.

\section{SIMPULAN DAN SARAN \\ Simpulan}

Perencanaan paket wisata budaya Desa Kesiman Kota Denpasar dapat dirancang dalam tiga paket wisata budaya sebagai simpulan berikut.

1. Paket Wisata History and Spirit of Kesiman Cultural Tour. Perkiraan waktu tempuh secara keseluruhan adalah 9 jam. Sedangkan biaya paket wisata untuk 1 pax adalah US\$ 145,2 pax adalah US\$ 85, 3 pax adalah US\$ 65, 4 sampai 6 pax adalah US\$60, dan untuk 7 sampai 9 pax adalah US\$ 54 .

2. Paket wisata Beautiful Art of Kesiman Cultural Tour. Perkiraan waktu tempuh secara keseluruhan adalah 8 jam 25 menit. Sedangkan biaya paket wisata untuk 1 pax adalah US\$147, 2 pax adalah US\$ 87, 3 pax adalah US\$ 67, 4 sampai 6 pax adalah US\$ 63, dan untuk 7 sampai 9 pax adalah US\$ 57.

3. Paket wisata Art and Local Activities of Kesiman Cultural Tour. Perkiraan waktu tempuh secara keseluruhan adalah 8 jam 15 menit. Sedangkan biaya paket wisata untuk 1 pax adalah US\$134, 2 pax adalah US\$ 82, 3 pax adalah US\$ 65, 4 sampai 6 pax adalah US\$ 62, dan untuk 7 sampai 9 pax adalah US\$ 59.

Saran

Berdasarkan simpulan diatas, dapat diberikan beberapa saran untuk pengembangan wisata budaya di Desa Kesiman, yaitu untuk memanfaatkan sumber daya manusia yang ada, yaitu pemandu wisata lokal atau local guide sehingga masyarakat lokal mendapatkan lapangan pekerjaan.

Pemerintah perlu membantu mengembangkan potensi wisata budaya masyarakat agar peran serta masyarakat dalam pariwisata meningkat.

\section{DAFTAR PUSTAKA}

Boniface P, 1995. Business and Economics. New York : Routledge 
Vol. 4 No. 1, 2016

Nototmojo Soekidjo, 2003. Ilmu Kesehatan Masyarakat. Jakarta : Rineka Cipta

Nuryanti. 1993. Concept, Perspectif and challenges, makalah bagian dari Laporan Konferensi International mengenai Pariwisata Budaya. Yogyakarta : Gajah Mada University Press

Suyitno, 2001. Perencanaan Wisata, Yogyakarta: Kanisius

Yoeti, Oka A. 1991. Pengantar Ilmu Pariwisata. Bandung: Angkasa

Yoeti, Oka A. 2002. Perencanaan Strategis Pemasaran Daerah Tujuan Wisata. Jakarta : Pradnya Paramita 